\title{
Primary monosymptomatic nocturnal enuresis and associated factors in a referral continence clinic of Abu Dhabi
}

\author{
Salvatore Arena, ${ }^{1}$ Mario Patricolo² \\ 1Unit of Paediatric Surgery, Department of Human Pathology in Adult and Developmental Age "Gaetano Barresi", \\ University of Messina, Messina, Italy; ${ }^{2}$ Department of Paediatric Surgery, Al Noor Hospital, Abu Dhabi, UAE
}

\begin{abstract}
The aim of the present study was to investigate the prevalence of primary monosymptomatic nocturnal enuresis (PMNE) and its associated factors in a major referral centre for nocturnal enuresis in the City of Abu Dhabi. Children referred to the Pediatric Continence Clinic of Department of Pediatric and Urology Surgery at Al Noor Hospital, Abu Dhabi (UAE), between January 2014 and January 2016 for the suspected diagnosis of NE were considered. The inclusion criteria of our study were: age 5-14 years; full medical history and physical examination; urine dipstick to exclude glycosuria and proteinuria; completion of diagnostic urological work-up; final diagnosis of PMNE. Parents were encouraged to follow a program on urotherapy. All children underwent renal and bladder ultrasound, abdominal X-ray and uroflowmetry with electromyography. Constipation was treated, if present. 39 patients had a diagnosis of PMNE. A constipation was present in 17 children (43.6\%). Statistical analysis documented a higher incidence of PMNE in the male groups. 38 out of 39 children (97.4\%) resolved PMNE, 14 following urotherapy and 24 required medical therapy with desmopressin. Our experience clearly confirms a higher prevalence rate of PMNE in boys than in
\end{abstract}

Correspondence: Salvatore Arena, Unit of Paediatric Surgery, Department of Human Pathology in Adult and Developmental Age "Gaetano Barresi”, University of Messina, Viale Gazzi, 98124 Messina, Italy.

Tel: +39.090 .2213014 .

Email: salarena@unime.it

Key words: Primary monosymptomatic nocturnal enuresis; Constipation; Continence.

Contributions: SA, study conception and design of the manuscript, writing up the draft of the paper; MP, critical revision of the article, approved final manuscript.

Conflict of interest: the authors declare no potential conflict of interest.

Received for publication: 20 February 2017.

Accepted for publication: 21 February 2017.

This work is licensed under a Creative Commons Attribution

NonCommercial 4.0 License (CC BY-NC 4.0).

CCopyright S. Arena and M. Patricolo, 2017

Licensee PAGEPress, Italy

La Pediatria Medica e Chirurgica 2017; 39:150

doi:10.4081/pmc.2017.150 girls. In the study population, the large intake of dry and reducedin-fibers foods, the excessive intake of carbonated drinks and the hot climatic condition might negatively influence the incidence of fecal retention and the subsequent PMNE. A multi-modal assessment seems to be effective in the management of PMNE, showing a very high rate of resolution.

\section{Introduction}

Acquisition of urinary control is a complex process in which the final stages are usually achieved at the age of 3 to 4 years when the majority of children develop an adult pattern of urinary control. ${ }^{1}$ According to Diagnostic and Statistical Manual and Mental Disorders (DSM) 5, nocturnal enuresis (NE) is defined as repeated voiding of urine into bed or cloche while asleep in children older than 5 years. ${ }^{2}$ Even if NE is considered a very common pediatric disorder, the estimated prevalence is highly variable from country to country.

According to its onset, ICCS classified NE as primary or secondary, where the term of primary NE (PNE) includes NE children that have never achieved urinary continence for a period of at least 6 consecutive months, whereas in secondary type NE, the disorders appears after the child has established a period of at least six consecutive months of urinary control. ${ }^{3}$ Moreover, NE is divided in monosymtomatic nocturnal enuresis (MNE) and nonmonosymptomatic nocturnal enuresis (NMNE), the latter associated with any other lower urinary tract symptoms and with a history of bladder dysfunction, in accordance with updated ICCS terminology. ${ }^{4}$ In this respect, it has been reported that $30-35 \%$ of enuretic children have a non-monosymptomatic form. ${ }^{5}$

$\mathrm{NE}$ can be responsible for behavioural, psychological and social problems including embarrassment, blushing, lack of self-esteem and aggression. ${ }^{6}$ Therefore, identifying children at risk and performing measures are necessary. ${ }^{6}$ Considering the importance and comorbidities as well as complications associated with $\mathrm{NE}$ and at the light of a lack of a comprehensive studies in this regards in the City of Abu Dhabi (UAE), our study aimed to investigate the prevalence of primary monosymptomatic nocturnal enuresis (PMNE) and its associated factors in the paediatric population, in a major referral centre for Nocturnal Enuresis, under the care of a single Consultant.

\section{Materials and Methods}

Children referred to the Pediatric Continence Clinic of Department of Pediatric and Urology Surgery at Al Noor Hospital - 
City of Abu Dhabi (UAE), between January 2014 and January 2016 for the suspected diagnosis of NE were considered. The inclusion criteria of our study were: age 5-14 years; full medical history and physical examination; urine dipstick to exclude glycosuria and proteinuria; completion of diagnostic urological work-up; final diagnosis of PMNE; follow-up of at least 6 months from the resolution of symptoms at the time of the visit to the outpatient clinic. Parents or children were invited to complete a frequency-volume chart to measure fluid intake and voided volume, for at least 2 days as well as episodes of NE, DTUI, other lower urinary tract symptoms (LUTS) and bowel movements, for at least 1 week. The parents were explained the normal bladder function and the pathogenesis of $\mathrm{NE}^{3}$ and were encouraged to follow a program on urotherapy based on international standards. Children were instructed to void regularly every two and $1 / 2$ hours during the day and always at bedtime. ${ }^{3}$ Correct toilet posture was optimized to allow relaxation if the pelvic floor muscles and a drawing of correct toilet sitting posture was given to each patient. Water and other caffeine-free drinks ad libitum were allowed during the day. Patients were also encouraged to eat fibre-rich food and recommended to maintain daily defecation of soft stools, with the help of the Bristol Stool Chart. All children underwent renal and bladder ultrasound to rule-out urogenital anomalies, abdominal X-ray to assess fecal load and/or spina bidifa occulta $(\mathrm{PBO})$ and uroflowmetry with electromyography (EMG) of the pelvic floor muscles and post-void residual US scan (PVR). Exclusion criteria were neuropathic bladder, anatomical abnormality affecting the bladder or the bowel, urethral and meatal stenosis, children primarily referred for UTIs, children with neurological and psychiatric problems, patients with primary non-monosymptomatic nocturnal enuresis, patients that did not complete the diagnostic protocol, patients with follow-up shorter than six months from the beginning of the therapy. Patients with constipation were treated with PEG 3350, at paediatric doses for oral faecal disimpaction, they were treated with desmopressin 120 or $240 \mathrm{mpg}$ one time a day at bed-time. Patients not responding to desmopressin were treated with anticholinergics (Tolterodine or Propiverine). Combinations were utilized as indicated in resistant cases to first line therapy.

\section{Results}

One-hundred twenty eight patients were referred at our Institution for the suspected diagnosis of NE, 82 males $(64 \%)$ and 46 females $(36 \%)$. In 35 males (mean age $8.8 \pm 2.1$ years) and 4 females (mean age 10.7 \pm 2.2 years) a PMNE was diagnosed $(30.5 \%)$. A constipation was present in 17 children $(43.6 \%), 15$ males and 2 females. A SBO was diagnosed in 2 patients $(5.1 \%)$ a male and a female. None had a story of UTI. Statistical analysis documented a significant higher incidence of PMNE in the male

Table 1. Effective management in males and females affected by primary monosymptomatic nocturnal enuresis.

\begin{tabular}{lcc} 
PNINE & Males & Females \\
Urotherapy + desmopressin & 11 & 2 \\
Urotherapy + desmopressin + PEG & 10 & 1 \\
\hline Urotherapy & 8 & 0 \\
Urotherapy + PEG & 5 & 1 \\
\hline Total & 34 & 4 \\
\hline
\end{tabular}

PMNE, primary monosymptomatic nocturnal enuresis; PEG, polyethylene glycol. groups as compared with the female one $(\mathrm{P}=0.0002) .38$ out of 39 children $(97.4 \%), 34$ out of 35 males and all female, resolved PMNE. In particular, 14 out of 39 (35.9\%) following urotherapy and treating constipation with PEG, if present while 24 required medical therapy with desmopressin. Resolution management is summarized in Table 1.

\section{Discussion}

Because the line is blurring between MNE and NMNE, our diagnostic assessment of children affected by PNE is based on a first clinical appraisal followed by bladder ultrasound, abdominal X-ray and uroflowmetry with electromyography (EMG). Our data confirms the findings that PMNE is prevalent among boys than girls $7-10$ while PMNE represents about $10 \%$ of PNE in female pediatric Abu Dhabi population.

We were surprised that more than $40 \%$ of children with PNME has a stool retention, without any significant different in the sex. It is reported that rectal distension due to fecal retention might cause bladder distortion and uninhibited bladder contraction which may lead to urinary tract symptoms, including nocturnal enuresis. ${ }^{11}$ However, our impression is that incidence of constipation in our study population is significantly higher, being previously reported at $7 \%$ in MNE affected patients. 12

Actually, we do not know the real influence of constipation in the pathogenesis of PMNE, but we believe that in the study population the large intake of dry and reduced in fibers foods such as rise and lemon, the excessive intake of carbonated drinks and the hot climatic condition might negatively influence the incidence of fecal retention and the subsequent PMNE. In our experience, urotherapy and bowel management resolved PMNE in more than one third of cases and the association with desmopressin was definitive in $97 \%$. We believe that the high rate of resolution of PMNE in our study is related to the pre-assessment investigations (urinalyses, uroflow with EMG, RBUS, abdominal X-Ray) in order to exclude unreported and undiagnosed symptoms and abnormalities. In this regards, even if diagnostic tools, excluding the clinical appraisal followed by a urine dipstick test, are not warrant as first line in the assessment of PMNE, ${ }^{3}$ we believe that this strategies carries a greater chance of success. Moreover, because NE affect child's self image, the relation with peers and parents and schooling, ${ }^{13,14}$ we suggest a more indepth evaluation of the problem, to reduce the incidence of failure and to accelerate the resolution.

\section{Conclusions}

In conclusion, it appears that associated factors in Abu Dhabi population are different from those in the studies conducted in other countries. Our experience clearly confirms a higher prevalence rate of PMNE in boys than in girls. A multi-modal assessment seems to be effective in the management of PMNE, showing a very high rate of resolution.

\section{References}

1. Muellner SR. Development of urinary control in children: a new concept in cause, prevention and treatment of primary enuresis. J Urol 1960;84:714-6. 
Short Communication

2. Ferrara P, Del Volga V, Romano V, et al. Combined Dietary Recommendations, Desmopressin, and Behavioral Interventions May Be Effective First-Line Treatment in Resolution of Enuresis. Urol J. 2015;12:2228-32.

3. Nevers T, Eggert P, Evans J, et al. Evaluation of and treatment for monosymptomatic enuresis: a standardization document from the International Children's Continence Society. J Urol 2010;183:441-7.

4. Nevéus T, won Gontard A, Hoebeke P, et al. The standardizatimon of terminology of lower urinary tract function in children and adolescents: report from the Standardisation Committee of the International Children's Continence Society. J Ural 2006; 176:314-24.

5. Butler R, Heron J, Alspac Study Team. Exploring the differences between mono- and polysymptomatic nocturnal enuresis. Scand J Urol Nephrol 2006;40:313-9.

6. Bakhtiar K, Pournia Y, Ebrahimzadeh F, et al. Prevalence of nocturnal enuresis and its associated factors in primary school and preschool children of khorramabad in 2013. Int J Pediatr 2014;2014:120686.

7. Semolic N, Ravnikar A, Meglic A, et al. The occurrence of primary nocturnal enuresis and associated factors in 5-year- old outpatients in Slovenia. Act Paediatr 2009;98:1994-8.

8. Butler RJ, Heron J. The prevalence of infrequent bedwetting and nocturnal enuresis in childhood. A large British cohort. Stand J Urol Nephrol 2008;42:257-64.

9. Kanaheswari Y. Epidemiology of childhood nocturnal enuresis in Malaysia. J Paediatr Child Health 2003;39:118-23.

10. Young CK, Sreedhar B, Shoe JD, et al. Differences in characteristics of nocturnal enuresis between children and addlescents: a critical appraisal from a large epidemiological study. BJU Int 2006;97:1069-73.

11. Dehghani SM, Basiratnia M, Matin M, et al. Urinary tract infection and enuresis in children with chronic functional constipation. Iran J Kidney Dis 2013;7:363-6.

12. Naseri M, Hiradfar M. Monosymptomatic and non-monosymptomatic nocturnal enuresis: a clinical evaluation. Arch Iran Med 2012;15:702-6.

13. Caldwell PH, Edgar D, Hodson E, Craig JC. Bedwetting and toileting problems in children. Med J Aust 2005;182:190-5.

14. Messina M, Molinaro F, Ferrara F, et al. Continence and duality of life with the modified Heitz-Boyer-Hovelacque rectal bladder for children with urinary incontinence following bladder exstrophy. J Pediatr Urol 2016;12:174.e1-6.

[page 38]

[La Pediatria Medic e Chirurgica - Medical and Surgical Pediatrics 2017; 39:150]

OPEN ACCESS 